\section{Fresh Nectarine Quality and Methyl Bromide Residues after In-package Quarantine Treatments}

\author{
R.T. Hinsch, C.M. Harris, P.L. Hartsell, and J.C. Tebbets \\ U.S. Department of Agriculture, Agricultural Research Service, \\ Horticultural Crops Research Laboratory, 2021 South Peach Avenue, \\ Fresno, CA 93727
}

Additional index words. export, Prunus persica, fumigation

\begin{abstract}
California nectarines [Prunus persica (L.) Batsch. var. nectarina (Ait) Maxim.] packed in single-layer corrugated fiberboard boxes were fumigated with methyl bromide (MB) at a rate of $48 \mathrm{~g} \cdot \mathrm{m}^{-3}$ for 21 hours at $21 \mathrm{C}$ and normal atmospheric pressure and a $50 \%$ load $(\mathrm{v} / \mathrm{v})$ as a quarantine treatment for codling moth (Cydia pomonella $\mathrm{L}$.$) .$ When the boxes were loosely stacked with spaces between them or tightly stacked and forced-air fumigated, concentration multiplied by time $(\mathrm{C} \times \mathrm{T})$ relationships were $>68$ $\mathbf{g} \cdot \mathbf{m}^{-3} \cdot \mathbf{h}^{-1}$, which is recommended for efficacy. Tightly stacked boxes that were not forced-air fumigated had $\mathrm{C} \times \mathrm{T}$ products $<68 \mathrm{~g} \cdot \mathrm{m}^{-3} \cdot \mathrm{h}^{-1}$. Organic bromide residues were $<0.001 \mu \mathrm{g} \cdot \mathrm{g}^{-1}$ and inorganic bromide residues were $<7.0 \mu \mathrm{g} \cdot \mathrm{g}^{-1}$ after 3 days. A trace to slightly phytotoxic response was observed in 'Summer Grand' and 'Fantasia' nectarines in 1989 but not in 1990.
\end{abstract}

The fresh nectarine industry would prefer to fumigate fruit for insect control after it has been graded, sorted by size, and packed rather than fumigating in field bins. Wainman et al. (1973) found that cardboard cartons presented little obstruction to methyl bromide (MB) when sugar was fumigated. Hale et al. (1977) showed that ethylene dibromide (EDB) concentrations in wirebound bins, fiberboard bins, and fiberboard boxes of grapefruit were almost the same. Penetration and sorption of $\mathrm{MB}$ in grapes varied by type of shipping container and packing method

Received for publication 17 July 1991. Accepted for publication 31 July 1992. The cost of publishing this paper was defrayed in part by the payment of page charges. Under postal regulations, this paper therefore must be hereby marked advertisement solely to indicate this fact.
(Harris et al., 1984). King et al. (1979) showed fiberboard carton material to be highly sorptive of EDB. Also, the rate of desorption of EDB was significantly faster from bulk nonwaxed citrus fruits than from packed fruit that had been waxed (Hartsell et al., 1986).

A MB fumigation treatment of $48 \mathrm{~g} \cdot \mathrm{m}^{-3}$ for $2 \mathrm{~h}$ at $\geq 21 \mathrm{C}$ and normal atmospheric pressure was developed as a quarantine treatment for the control of codling moth eggs on six cultivars of midseason nectarine by Yokoyama et al. (1987, 1988). Using this treatment schedule, Harvey et al. (1982) found that MB injury can be expected on some of the cultivars but that this injury can be reduced by fumigating fruit before it has been run over commercial grading and sorting lines for packing. Also, more injury developed in fruit that was fumigated at $4.5 \mathrm{C}$ than in fruit treated at $26.5 \mathrm{C}$. They concluded that nec- tarines should be fumigated in field bins shortly after harvest and before being passed over conveyor lines for packing and subsequent cooling.

The objectives of our investigations were to: 1) determine the sorption and desorption rates of $\mathrm{MB}$ from fumigated nectarines packed in corrugated fiberboard boxes; 2) measure MB residues in the nectarines; 3 ) evaluate the quality of the nectarines after their fumigation in corrugated fiberboard boxes; and 4) correlate data for objectives 1-3 with data for fumigation of fruit in field bins [i.e., data that were used to establish the quarantine treatment (Hartsell et al., 1992)].

In-package fumigation tests conducted in 1989 included two replications of "May Grand' and three each of 'Summer Grand' and 'Fantasia' nectarines. In the orchard, all the fruit for these tests had been picked from the trees, placed into buckets, and transported by farm trailer to the packing shed, where the fruit was hand sorted and sized and placed directly into fiberboard boxes. The fruit did not pass over conveyor lines, and was not washed, waxed, or treated with postharvest fungicides. The nectarines were kept overnight at $21 \mathrm{C}$ so all fruit would be at the same temperature when fumigated.

In 1990, there were three replications each of 'May Grand', 'Summer Grand', 'Fantasia', and 'September Grand'. All fruit were

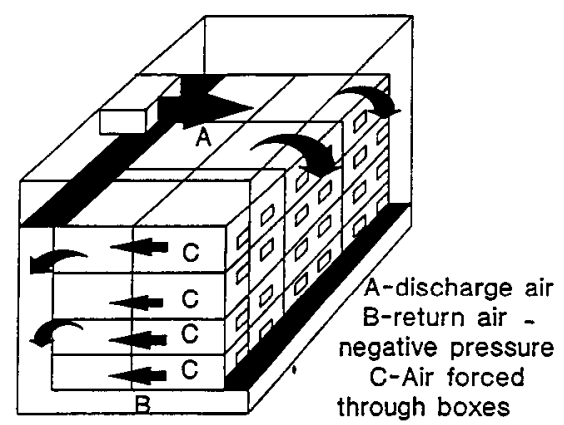

Fig. 1. Example of a forced-air treatment chamber used for the fumigation tests. 


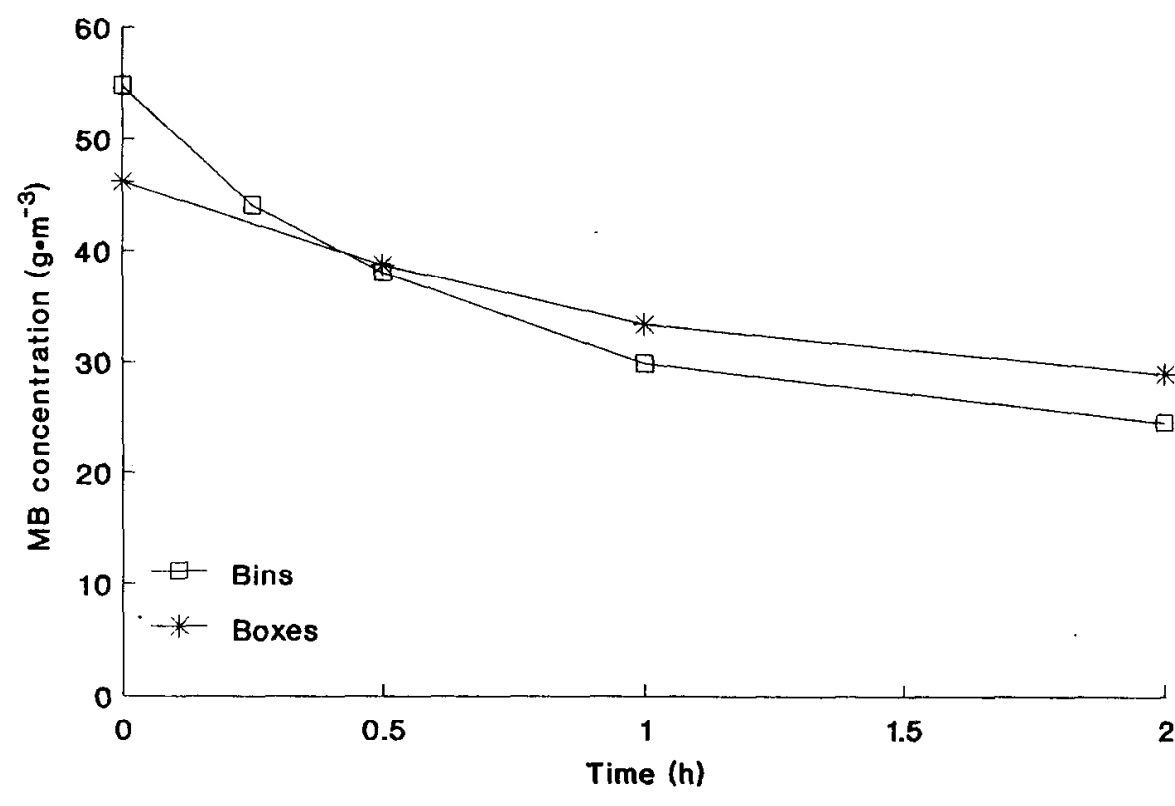

Fig. 2. Mean methyl bromide (MB) concentrations of nectarines in boxes or field bins that were fumigated with $\mathrm{MB}$ at $48 \mathrm{~g} \cdot \mathrm{m}^{-3}$ for $2 \mathrm{~h}$ at $21 \mathrm{C}$ and atmospheric pressure with a $50 \%$ load $(\mathrm{v} / \mathrm{v})$. Data are means of 17 tests with boxes (1989-90) and eight tests with bins (1986-87).

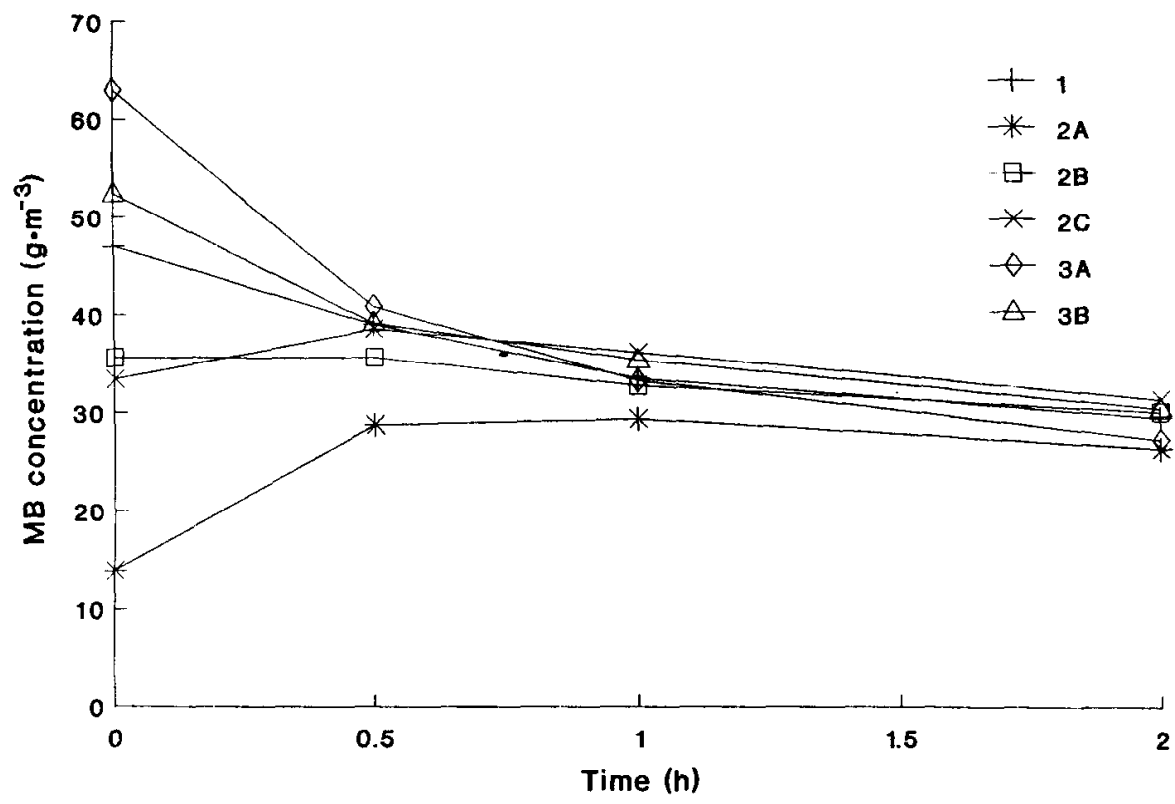

Fig. 3. Methyl bromide concentrations inside boxes when fumigated with $48 \mathrm{~g} \cdot \mathrm{m}^{-3}$ for $2 \mathrm{~h}$ at $21 \mathrm{C}$ and atmospheric pressure with a $50 \%$ load $(\mathrm{v} / \mathrm{v}): 1)$ loosely stacked boxes with eight vents $(1.6 \times$ $4.4 \mathrm{~cm}) ; 2)$ tightly stacked boxes with A) eight vents $(1.6 \times 4.4 \mathrm{~cm}), \mathrm{B})$ eight vents $(3.2 \times 4.4$ $\mathrm{cm})$, C) 12 vents $(1.6 \times 4.4 \mathrm{~cm})$; and 3$)$ tightly stacked boxes with eight vents $(1.6 \times 4.4 \mathrm{~cm})$ and forced-air fumigated at a rate of A) $2.6 \mathrm{~m}^{3} \cdot \mathrm{min}^{-1}$, B) $5.7 \mathrm{~m}^{3} \cdot \mathrm{min}^{-1}$. Data are means for 13 tests, 1990.

picked into bulk bins and transported by truck to the packinghouse. The noncooled fruit was mechanically dumped onto the grading table, washed, sprayed with food grade wax, mechanically sorted and sized, and packed in fiberboard boxes. No postharvest fungicides were applied.

All fruit were packed in corrugated fiberboard, bliss-style boxes $(37.5 \times 41.5 \times$ $11.5 \mathrm{~cm}$ ) designed for one layer of fruit. A thermo-formed, polyvinyl chloride tray with individual cups held from 25 to 32 pieces of fruit, which weighed $\approx 5 \mathrm{~kg}$. Two pads filled with macerated paper were placed in each boxes were then stacked on the floor of the chamber behind the pallet for a total of 80 boxes, the number required to occupy $50 \%$ load $(\mathrm{v} / \mathrm{v})$ within the $3.12-\mathrm{m}^{3}$ fumigation chamber. There were 25.6 boxes $/ \mathrm{m}^{3}$ containing $\approx 128 \mathrm{~kg}$ of fruit. This ratio compares to $\approx 179 \mathrm{~kg} \cdot \mathrm{m}^{-3}$ for nectarines fumigated in bulk bins (Hartsell et al., 1992). For the remaining cultivars during the 1990 season, the packed boxes in the chamber were kept tightly together on the pallet with four corner boards and two horizontal and two vertical straps. To improve the circulation of the MB under these tightly stacked conditions, two additional rectangular ventilation slots (1.6 $\times 4.4 \mathrm{~cm}$ ) were cut into the end panels of the boxes packed with 'Fantasia'. For three of the tests with 'September Grand', the boxes had the ventilation slots in the side increased to $3.2 \times 4.4 \mathrm{~cm}$

The fruit, boxes, and pallet were fumigated with $\mathrm{MB}$ at a dose of $48 \mathrm{~g} \cdot \mathrm{m}^{-3}$ for 2 $\mathrm{h}$ at $21 \mathrm{C}$ and normal atmospheric pressure. The chamber exceeded the positive-pressure certification required for tightness (U.S. Dept. Agriculture, 1976) and was equipped with a fan that circulated air at the rate of 5.72 $\mathrm{m}^{3} \cdot \mathrm{min}^{-1}$ and that ran continuously during the exposure period. Sampling tubes to measure MB concentrations were placed inside the boxes at the top back, middle center, and bottom front of the chamber. One additional tube was placed in the air return duct. Temperature probes were inserted into the pulp of fruit that were located near the sampling tubes. Fruit temperatures were monitored during fumigation with a scanning tele-thermometer Model 47 (Yellow Springs Instrument, Yellow Springs, Ohio).

In another experiment with 'September Grand', which was replicated four times, the interior of the fumigation chamber was modified so that the boxes of fruit could be fumigated with forced-air (Fig. 1). Each box had four rectangular ventilation slots $(1.6 \times$ $4.4 \mathrm{~cm}$ ) on each of two sides that were positioned $90^{\circ}$ to the direction of the air/gas flow. Air pressure was measured with a Utube manometer, and the sampling tube was located in the return air space. Three fumigations were conducted with air that circulated at the rate of $5.72 \mathrm{~m}^{3} \cdot \mathrm{min}^{-1}$, with a negative pressure of $19.1 \mathrm{~mm}$ water, and one test was conducted with an air circulation rate of $2.60 \mathrm{~m}^{3} \cdot \mathrm{min}^{-1}$, with a negative pressure of $9.6 \mathrm{~mm}$ water, or $233 \times 10^{-6} \mathrm{~m}^{3} \cdot \mathrm{s}^{-1}$ and $100 \times 10^{-6} \mathrm{~m}^{3} \cdot \mathrm{s}^{-1}$ of air, respectively, per kilogram of fruit.

Moisture content of the fiberboard boxes, taken with a Delmhorst moisture meter (model PA-1 Delmhorst Instrument, Boonton, N.J.), ranged from $7.5 \%$ to $8.5 \%$. The wood pallets had a moisture content of $8 \%$.

Concentrations of $\mathrm{MB}$ within the chambers were determined by a gas-liquid chromatograph (GLC) with a flame ionization detector. The gas samples were introduced into the GLC via an integral gas sampling valve with a 100 -ml gas syringe, as described by Tebbets et al. (1983). Concentrations of MB in the chambers were determined $\approx 1$ min after introduction of the chemical 


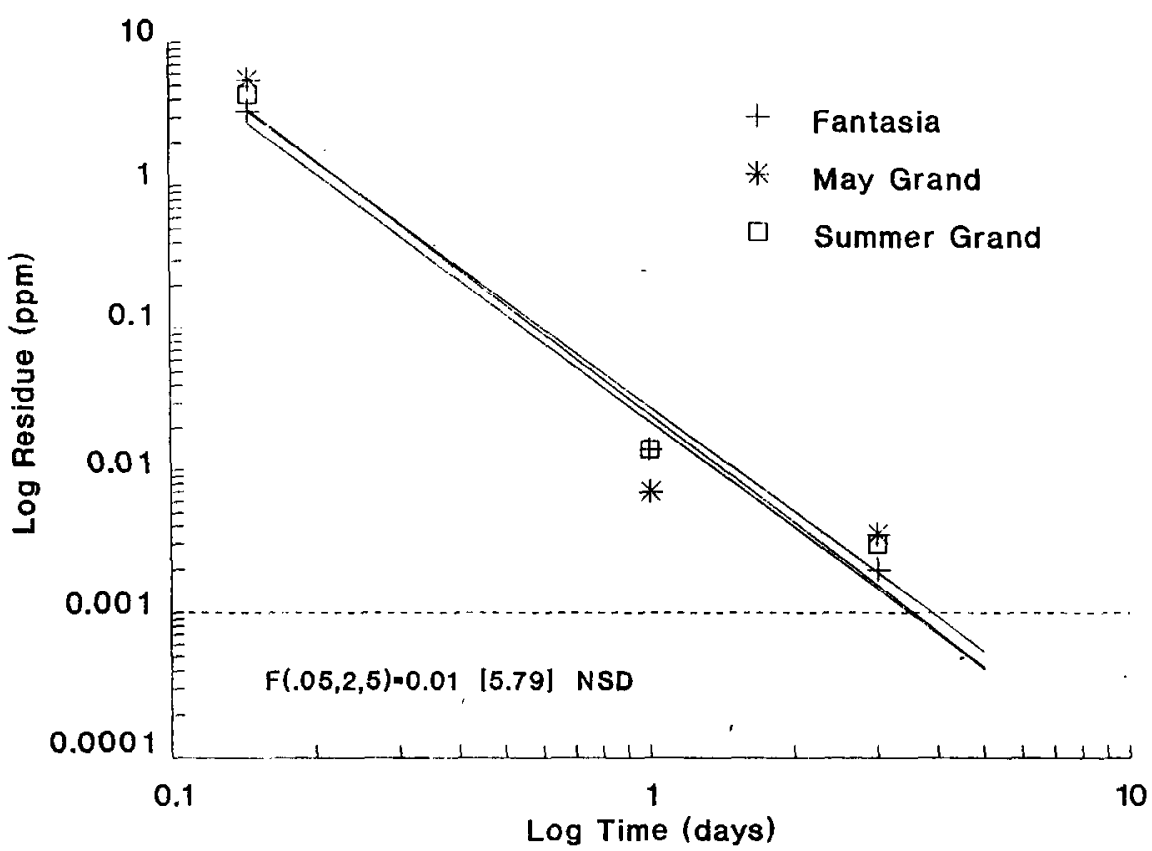

Fig. 4. Methyl bromide residues in three cultivars of nectarines following fumigation with $48 \mathrm{~g} \cdot \mathrm{m}^{-3}$ for $2 \mathrm{~h}$ at $21 \mathrm{C}$ and normal atmospheric pressure with a $50 \%$ load $(\mathrm{v} / \mathrm{v})$ as a function of storage time at 2.5C. Data are means for eight tests in 1989 and nine in 1990.

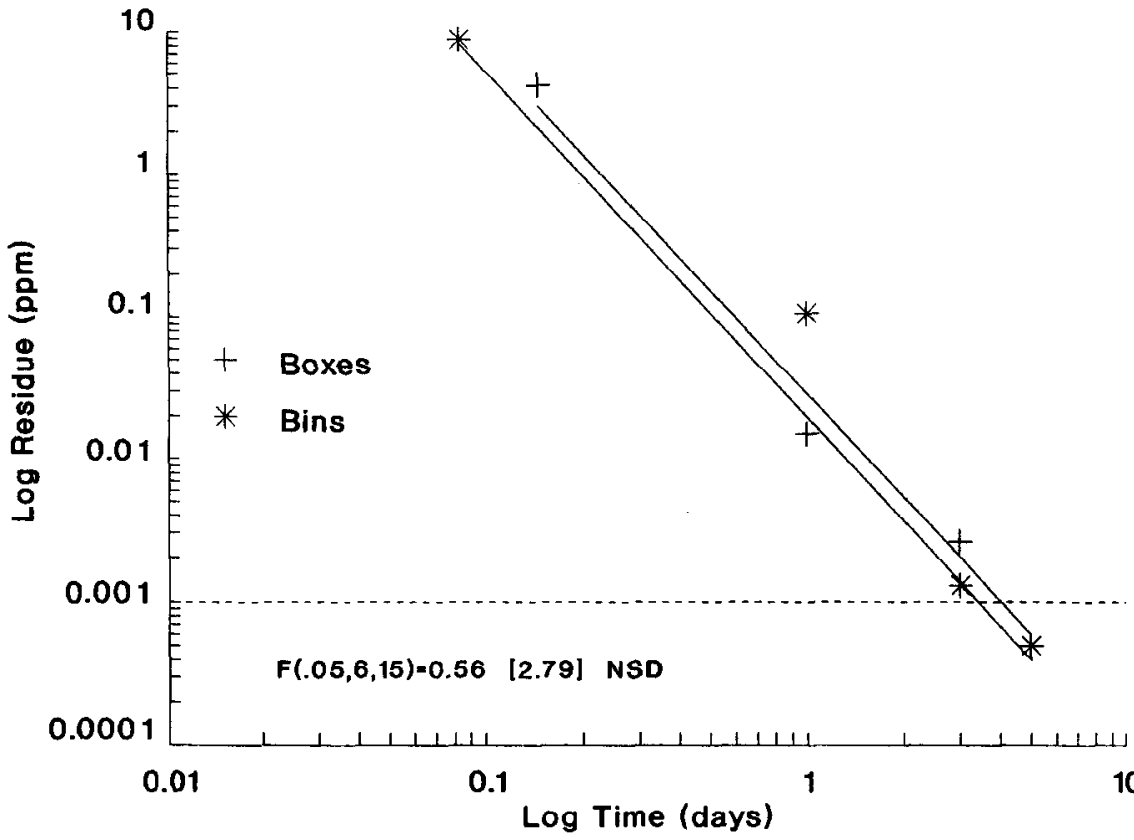

Fig. 5. Mean desorption of residual methyl bromide of nectarines treated in field bins or boxes following fumigation with $48 \mathrm{~g} \cdot \mathrm{m}^{-3}$ for $2 \mathrm{~h}$ at $21 \mathrm{C}$ and normal atmospheric pressure with a $50 \%$ load $(\mathrm{v} / \mathrm{v})$. Data are means of 17 tests with boxes (1989-90) and eight tests with bins (1986-87).

and after $0.5,1.0$, and $2.0 \mathrm{~h}$. Percent sorption was calculated from initial and final concentrations of $\mathrm{MB}$ in the chamber. Concentrations are presented as $\mathrm{C} \times \mathrm{T}$ products and expressed as grams per cubic meter per hour. The $\mathrm{C} \times \mathrm{T}$ products were calculated in a manner similar to that described by Monro (1969).

After fumigation, the chamber and contents were aerated (forced air was used for the second test with 'September Grand') until MB concentrations in the return air duct were reduced to $<5 \mu \mathrm{g} \cdot \mathrm{g}^{-1}$. Samples of the treated and control fruit were taken immediately for analysis of organic bromide residues. The remainder of the test fruit was stored at 2.5C for up to 7 days for additional organic bromide residue, and for 7 days for inorganic bromide residues and quality determinations for all cultivars except 'September Grand'. Organic bromide residues were determined in the fruit immediately after aeration and after 1, 3, 5, and 7 days of storage at $2.5 \mathrm{C}$ until levels decreased to 0.001 $\mu \mathrm{g} \cdot \mathrm{g}^{-1}$. The gas-solid chromatography headspace method used for this analysis was described by Hartsell et al. (1992). Desorption rates of residual MB are expressed as log regression curves using the power curve: $y$ $=a x^{b}$, where $\mathrm{x}=$ time of analysis after 2 $\mathrm{h}$ aeration and $\mathrm{y}=$ residual value $\left(\mu \mathrm{g} \cdot \mathrm{g}^{-1}\right)$. Analysis of covariance (Dixon and Massey,
1969; Draper and Smith, 1981) was used to compare desorption rates between cultivars tested. An X-ray fluorescence spectrophotometer (Spectrace 431, Tracer Northern, Middleton, Wis.) was used for determining inorganic bromide residues in the fruit as described by Harvey et al. (1989).

Three sample boxes of nectarines from each fumigation test were inspected visually for MB injury as described by Harvey et al. (1982) and for other defects, such as bruising and cuts. These defects were rated on a scale of $0=$ no injury to $5=$ extensive injury. Firmness was measured at the equator of the fruit using a pressure tester with an 8-mm plunger. Soluble solids content (SSC) was measured by a refractometer.

In preliminary tests, we found that empty boxes sorbed $\approx 35 \%$ more MB than empty bins (Hartsell et al., 1992) based on a 50\% load (v/v) in the chamber. When boxes and bins were fully loaded with fruit, the bins with fruit sorbed $\approx 34 \%$ more MB than the boxes with fruit because fruit density was higher in the bins than in the boxes. The greater MB sorption by the box material was about equal to the MB sorption by the additional fruit in the bins. However, the boxes that were loosely stacked averaged 70.4 $\mathrm{g} \cdot \mathrm{m}^{-3} \cdot \mathrm{h}^{-1} \pm 1.6 \mathrm{SD}$ and was almost the same as that for the bins; 67.2 \pm 2.1 (Fig. 2). The $\mathrm{C} \times \mathrm{T}$ values for boxes that were loosely stacked were 71.0 , while those for boxes that were tightly stacked averaged only 49.0. The $\mathrm{C} \times \mathrm{T}$ products for boxes that were tightly stacked and had additional ventilation slots in the box ends or enlarged side vent holes averaged 69.0 and 66.0 , respectively. The $\mathrm{C} \times \mathrm{T}$ products for the boxes that were forced-air fumigated at 5.72 or at $2.60 \mathrm{~m}^{3} \cdot \mathrm{min}^{-1}$ averaged 74.0 and 75.0 , respectively. Yokoyama et al. (1990) proposed that a $\mathrm{C} \times \mathrm{T}$ product of $68.0 \pm 3.0$ $\mathrm{g} \cdot \mathrm{m}^{-3} \cdot \mathrm{h}^{-1}$ would be a useful measurement to maintain treatment security for control of codling moth eggs on all cultivars of nectarines. With the forced-air system, the MB concentration was reduced to $5 \mu \mathrm{g} \cdot \mathrm{g}^{-1}$ within $2.5 \mathrm{~h}$, whereas $3.5 \mathrm{~h}$ was required by normal aeration. The lower $\mathrm{C} \times \mathrm{T}$ products found in the tight stacks were caused by slowed penetration of MB through the box vents, whereas those loosely stacked allowed MB access between the individual boxes. Tightly stacking the boxes with retaining straps and using forced-air fumigation eliminated the problem with slow MB penetration (Fig. 3).

$\mathrm{MB}$ desorbed rapidly from fruit packed in boxes and equally (slope $\mathrm{F}=0.01$ ) for all three cultivars tested (Fig. 4). After 3 days of storage at $2.5 \mathrm{C}$, residues were $<0.001$ $\mu \mathrm{g} \cdot \mathrm{g}^{-1}$. Similarly, when mean regression lines of all cultivars from the box and the bin tests were compared, the rates of desorption were similar (Fig. 5).

Inorganic bromide residues were well below the U.S. tolerance of $20 \mu \mathrm{g} \cdot \mathrm{g}^{-1}$. 'Summer Grand' had the highest $(6.4 \pm 0.4$ $\left.\mu \mathrm{g} \cdot \mathrm{g}^{-1}\right)$, 'Fantasia' the lowest $(5.8 \pm 0.5$ $\left.\mu \mathrm{g} \cdot \mathrm{g}^{-1}\right)$, and 'May Grand' was intermediate $\left(6.2 \pm 0.8 \mu \mathrm{g} \cdot \mathrm{g}^{-1}\right)$. All controls contained $<2 \mu \mathrm{g} \cdot \mathrm{g}^{-1}$ inorganic bromide. In addition, 
mean residue values for all cultivars tested in boxes compared favorably with means of those treated in bins, $6.1 \pm 0.6$ and $6.3 \pm$ $0.2 \mu \mathrm{g} \cdot \mathrm{g}^{-1}$, respectively.

The quality and condition of the nectarines after fumigation in boxes and 7 days of storage at $2.5 \mathrm{C}$ were nearly the same as those of the control fruit. In 1989, when the fruit was hand sorted and sized, firmness ranged from 28 to $43 \mathrm{~N}$, while SSC ranged from $9.1 \%$ to $12.2 \%$. In 1990 , when the fruit was mechanically sorted and sized, firmness ranged from 46 to $76 \mathrm{~N}$, while SSC ranged from $9.9 \%$ to $11.4 \%$. Incidence and severity of defects, such as bruising and cuts, were also similar. Differences in firmness, SSC, and defects between the fumigated and nonfumigated fruit were not significant.

'May Grand' was not damaged by MB, while 'Summer Grand' showed a trace and 'Fantasia' slight phytotoxicity in 1989 but none in 1990. Bruising and cuts were more common in the control nectarines than in the fumigated nectarines. Differences in MB damage and other defects were not significant.

A major concern about fumigating fruit in packed boxes has been the high MB sorptive properties of fibrous materials. However, the density of packed fruit is less than that of bulk fruit, and $\mathrm{C} \times \mathrm{T}$ products for both were nearly the same. The fumigation treatment likely would be effective against codling moth as long as the boxes were loosely stacked with spaces between them in the fumigation chamber, or forced-air circulation was used during fumigation so that initial concentrations are sufficient to provide a $\mathrm{C} \times \mathrm{T}$ product that will maintain the security for control of codling moth.

Residues (organic and inorganic bromide) in nectarine cultivars fumigated in boxes were nearly equal to those in fruit from the bin tests and therefore do not exceed those allowed for export fruit.

California nectarines fumigated after being packed in fiberboard boxes showed no significant damage from $\mathrm{MB}$ and would be acceptable to the fresh fruit and vegetable trade. The ability to fumigate packed fruit selected for export would reduce a shipper's costs because only fruit destined for countries that have a quarantine against codling moth would need to be fumigated. Fruit not needing fumigation could continue to be handled by current commercial methods.

\section{Literature Cited}

Dixon, W.J. and F.J. Massey, Jr. 1969. Introduction to statistical analysis. 3rd ed. McGrawHill, New York,

Draper, N.R. and H. Smith. 1981. Applied regression analyses. 2nd ed. Wiley, New York.

Hale, P.W., W.R. Miller, D.L. von Windegut, and J. King. 1977. Ethylene dibromide fumigation of grapefruit packed in tray-packed containers and in bulk bins. Proc. Fla. State Hort. Soc. 90:148-151.

Harris, C.M., J.M. Harvey, and D.C. Fouse. 1984. Penetration and retention of methyl bromide in packaged table grapes. Amer. J. Enol. \& Viticult. 35:5-8.

Hartsell, P.L., C.M. Harris, P.V. Vail, J.C. Tebbets, J.M. Harvey, V.Y. Yokoyama, and R.T.
Hinsch. 1992. Toxic effects and residues in six nectarine cultivars following methyl bromide quarantine treatment. HortScience 27:12861288

Hartsell, P.L., J.S. Tebbets, and J.C. Tebbets. 1986. Ethylene dibromide fumigation of California-grown citrus: Effects of fumigating unpacked, bulk fruits, or commercially-packed fruits on applied dosages and residues. J. Econ. Entomol. 79:166-171

Harvey, J.M., C.M. Harris, and P.L. Hartsell. 1982. Commodity treatments: Responses of nectarines, peaches, and plums to fumigation with methyl bromide. U.S. Dept. Agr. Agr. Res. Serv. Mktg. Res. Rpt. 1124, Washington, D.C.

Harvey, J.M., C.M. Harris, and P.L. Hartsell 1989. Tolerances of California nectarine cultivars to methyl bromide quarantine treatments. J. Amer. Soc. Hort. Sci. 114:626-629.

King, J.R., D.L. von Windegut, and A.K. Burditt, Jr. 1979. Residues of ethylene dibromide present in fumigated fiberboard carton material. Proc. Fla. State Hort. Soc. 92:162-165.

Monro, H.A.U. 1969. Manual of fumigation for insect control. 2nd ed. Food Agr. Org. Agr. Study 79, Rome.

Tebbets, J.S., P.L. Hartsell, H.D. Nelson, and J.C. Tebbets. 1983. Methyl bromide fumiga- tion of tree fruits for control of Mediterranean fruit fly: Concentrations, sorptions, and residues. J. Agr. Food Chem. 31:247-249.

U.S. Department of Agriculture. 1976. Plant protection and quarantine treatments manual. Section II. U.S. Dept. Agr., Washington, D.C.

Wainman, H.E., H.K. Haseltine, and R.W. Taylor. 1973. The fumigation of white sugar in packets with methyl bromide. J. Stored Products Res. 9:71-76.

Yokoyama, V.Y., G.T. Miller, and P.L. Hartsell. 1987. Methyl bromide fumigation for quarantine control of codling moth (Lepidoptera:Tortricidae) on nectarines. J. Econ. Entomol. 80:840-842.

Yokoyama, V.Y., G.T. Miller, and P.L. Hartsell. 1988. Rearing, large scale tests and egg response to confirm efficacy of a methyl bromide quarantine treatment for codling moth (Lepidoptera:Tortricidae) on exported nectarines. J. Econ. Entomol. 81:1437-1442.

Yokoyama, V.Y., G.T. Miller, and P.L. Hartsell. 1990. Evaluation of methyl bromide quarantine treatments to control codling moth (Lepidoptera:Tortricidae) on nectarine cultivars proposed for export to Japan. J. Econ. Entomol. 83:460-471. 